\title{
Multi-stakeholder analysis to improve agricultural water management policy and practice in Malta
}

D.D’Agostino, M.Borg, S.H.Hallett, R.S.Sakrabani, A.Thompson, L.Papadimitriou, J.W.Knox

\begin{abstract}
Malta faces a raft of water challenges which are negatively impacting on the sustainability of irrigated agriculture, and creating serious tensions with other sectors competing for water, including urban development, tourism and the environment. In this paper we argue for a transparent process centred on participatory stakeholder engagement to agree on the most challenging water-related risks and to identify solutions that both support the water governance framework and improve on-farm water management practices. Given Malta's dependence on freshwater, this study focused on outdoor field-scale irrigated production. A three staged stakeholder-driven approach was developed. The first stage included Delphi analyses to identify the key constraints on water management and fuzzy cognitive mapping to enable stakeholders to analyse their mental models and formalise conceptual and causal relationships between different components impacting on Maltese agriculture. Secondly, questionnaires were used to inform understanding of national policy gaps in water management and thirdly, a "backcasting" stakeholder workshop was used to identify policy actions to achieve a more sustainable future for agriculture on the island. The study confirmed that Malta's core challenge is tied to poor water governance and the need to define policies that are socially and environmentally acceptable and geared to tackling the complex water challenges the agricultural sector faces. Developing support for farmer training, knowledge translation, greater public awareness of the importance and value of water for high-value crop production and multi-sector collaboration to promote shared opportunities for water infrastructure investment were highlighted as potential solutions. The findings have direct relevance to other island communities where water scarcity poses serious agronomic risks to production and where agriculture underpins rural livelihoods and the economy.
\end{abstract}

Keywords: climate change; groundwater; irrigation; risk; water resources

\section{Introduction}

Malta is the most water-scarce country in Europe, and ranked in the top ten globally in terms of water scarcity (MBB, 2014). It has virtually no exploitable surface water resources, with 
supplies being heavily dependent on groundwater and desalination (Conrad and Cassar, 2014). The former is under intense pressure due to over-abstraction with rates considered unsustainable based on current rainfall-recharge estimates (MBB, 2014). The impacts of a changing climate on agriculture with greater rainfall uncertainty and increased drought risk will exacerbate the current situation (MEPA, 2011; Roberts et al., 2015). Malta's entry into the EU in 2004 added pressure for stronger engagement in environmental policy formulation, specifically through its statutory requirement under the Water Framework Directive (WFD) (Xerri et al., 2016). The entire island of Malta is designated as being within a nitrate vulnerable zone so improved water management is critical not only in terms of meeting future water demands but also for compliance with European regulations to minimise agricultural pollution. Irrigated agriculture accounts for nearly three-quarters of all groundwater abstractions despite representing only $15 \%$ of the total agricultural land area (Attard et al., 2007). However, there is currently limited geospatial data on agricultural abstractions including the actual locations and volumes of water used, with all estimates of abstraction being based on sources of varying quality (FAO, 2006; MEPA, 2011). Widespread illegal groundwater abstraction is also known to occur, which is not captured in government records (Conrad and Cassar, 2014).

Understanding the current nature of demand, likely changes due to agricultural intensification, climate change and socio-economic development and their consequent impacts on the islands' water resources constitutes a national strategic and environmental priority.

Although agriculture accounts for the dominant use of groundwater, there is increasing competition from other sectors, notably for public water supply (urban expansion), and tourism. To date, efforts to reduce water consumption and improve efficiency have been implemented within the leisure and business sectors (MBB, 2014), but efforts to tackle the equivalent use in agriculture has not been successful (Roberts et al., 2015). In the context of developing an environmentally sustainable agricultural sector in Malta, Dwyer et al. (2014) reported on the need to reduce groundwater abstraction significantly, as well as promoting higher water efficiency and groundwater substitution with greywater.

Several physical and economic barriers to increasing water productivity currently exist in Malta, including coping with existing water scarcity, the rising cost of productive land, land fragmentation and high labour costs (Papadimitriou et al., 2019). Given the relatively low cost of groundwater (farmers only pay for pumping, with no administrative costs) and lack of an effective regime for abstraction management, these underlying factors have inevitably contributed to over-abstraction and aquifer degradation. Limitations in water supply have also 
constrained opportunities to improve crop productivity. With an increasingly competitive market, irrigation has become an essential component of production to increase yield and assure quality. Meeting stringent specifications from retailers and the supply chain have thus become important "drivers for change" particularly for high-value horticultural fruits and vegetables. Considering Malta's strategic location between Europe and northern Africa, improving food security is also essential given agriculture's role in local value chains. Rising consumer demands for premium quality food are also being driven by an expanding tourism sector and socio-economic development.

Whilst the water scarcity and aquifer pressures on Malta are well documented, there remains widespread contention regarding the choices available to ameliorate the problem (Roberts et al., 2015). The government's ability to manage water issues and its vision for a sustainable future was reported to lack transparency and trust (Xerri et al., 2016) with the water crisis being largely due to a lack of sound governance (FAO, 2006). The main issues relate to separated water and agriculture policies, a fragmented decision-making process, low levels of stakeholder engagement and a low awareness of the consequences of mismanagement of water (Zammit, 2006). A need for improved consultation and engagement with rural stakeholders was also identified in the recent National Agricultural Policy for the Maltese Islands for 2018 to 2028 (MESDC, 2018). Farmers and other rural stakeholders have been reported to frequently complain that prospective development projects rarely engage their sector perspectives. For example, one major water project that was recently launched involving the distribution of treated sewage effluent to farmers was heavily criticized by rural stakeholders due to the absence of any form of consultation regarding the project's design and implementation. The situation is compounded by the limited degree to which agriculture plays a role in national water resources dialogue, despite the high proportion of water demand used by agriculture (Gatt, 2016). Moreover, a critical barrier in improving resource efficiency and crop productivity in Malta has been the lack of a training service for its farmers whilst extension services are still in their infancy (Swanson, 2008).

Malta therefore needs to adopt improved management practices to reconcile the fundamental water challenges it faces through the implementation of a long-term strategic plan for water. However, sound water governance requires active stakeholder participation via effective channels that will engender high levels of social inclusion and trust to support policy implementation. Stakeholder engagement in decision-making is strongly advocated within the Water Framework Directive, as a prerequisite for effectively tackling environmental problems 
(EC, 2000). Participatory approaches can be used to involve stakeholders at an early stage in the decision making process, which has the benefit of incorporating stakeholder perspectives into the debate and improving the social acceptance of policy measures (Khadra et al., 2011; Saliba et al., 2018; van Vliet et al., 2017).

In the context of a broader study on innovations in Maltese agriculture (Hallett et al., 2017), here we examine stakeholders' perceptions on the key issues and potential solutions for improving agricultural water management in Malta. The rationale was to provide stakeholderbased evidence to support the development and implementation of robust policies to support more sustainable future irrigated agricultural management practices in Malta.

\section{Material and Methods}

Our analysis consisted of a three staged participatory stakeholder-driven approach. Firstly, a workshop in Malta involving key informants was organised. This involved a qualitative Delphi analysis (Alcon et al., 2014; Nowack et al., 2011) and a semi-qualitative fuzzy cognitive mapping (FCM) exercise (Khadra et al., 2011; Kosko, 1993). A process of stakeholder consultation via an online questionnaire was then used to follow up on the first workshop, with an emphasis on the Maltese policy framework. The final stage involved a follow-up stakeholder workshop which drew on the evidence from the Delphi and FCM exercises and questionnaire data in order to conduct a "backcasting" exercise. This was to identify the specific policy actions from a stakeholder perspective needed to attain a future sustainable outcome defined as "adequate water availability for the future of agriculture in the 2030s".

\subsection{Stakeholder Delphi analysis and fuzzy cognitive mapping}

This exercise was designed to gather information regarding stakeholder perceptions and sentiment on the water-related problems and risks facing the irrigated agricultural sector. This included the relevance of current policies and identification of actions needed to improve the future sustainability of water resources for agriculture. The process aimed to facilitate stakeholders with different values and goals to form a clear shared opinion and balanced view on both current and future challenges. The workshop involved 22 participants carefully selected to represent all relevant stakeholder groups including policy makers, water regulators, farmers and representatives from the agrifood industry, environmentalists, academics and researchers. The participants were introduced to the stakeholder elicitation process and the notion of system boundaries and system variables. The ambiguity and complexity of traditional decision-making processes was highlighted and the advantages and limitations of stakeholder engagement were discussed. Two established techniques including Delphi analysis and FCM 
were used to gather insights from the stakeholders and to structure the debate and discourse from both a qualitative and quantitative perspective. The approach adopted a similar methodology to that described by Khadra et al., (2011) and van Vliet et al. (2017, 2010).

Delphi analysis is a method that helps to organise the communications from a group as part of an expert-consultation process, so that individual participants can directly contribute to resolving a complex problem (Nowack et al., 2011). Delphi has two main characteristics. First, it is based on controlled feedback, as each participant is introduced to the responses acquired in former rounds of consultation and can thus adjust their own viewpoint after being informed by the outlook from the rest of the group. Second, it is a method that allows quantitative analysis of the qualitative information collected from the group (Alcon et al., 2014).

In the first Delphi analysis exercise, the meta-planning technique was used. This technique encourages individuals to visually express their thoughts on the issue being discussed by writing key words or key concepts onto notes and then arranging these into clusters on a shared space. Participants were divided into two groups in which each stakeholder category was equally represented, with each group supported by a moderator and rapporteur to ensure maximum engagement. This approach provided an opportunity for open discussion. All opinions were recorded and the outcomes from each group were then discussed in two plenary sessions. Evidence from the Delphi analysis was then used to support the FCM exercise. A FCM consists of concepts representing key factors (variables) of a system, joined by directional lines graphically representing causal relationships (connections) between nodal concepts (Kosko, 1993). There is a causal relation between two given concepts when a change in one of those concepts affects the other one. The result of a causal effect is always a variation in one or more concepts. In FCM there are two kinds of causality: positive and negative. If an increase in concept A causes an increase in concept $\mathrm{B}$, then causality is positive. If an increase in concept A causes concept B to decrease, then causality is negative. The amount of change is defined by a weight between concepts (Carvalho and Tomè, 1999). The main advantage of FCM is that they are easy to construct and provide qualitative results for understanding perceptions and therefore social ideas of how systems operate. They can be constructed based on observations and do not make quantitative predictions but rather show what will happen to the system under given conditions of different relationships between variables. FCM can be developed in different ways: e.g. manually based on the acquired knowledge, by using automatic methods or also by employing a set of computer-based tools (Carley and Palmquist, 1992; Roberts, 2015; Schneider et al., 1998). 
During the FCM exercise, the 22 stakeholders were asked to represent (i) the cause-effect relationships (arrows) between all identified issues (clusters of problems or clusters of solutions), (ii) the strength of the causal links, expressed through different thickness of the arrowed lines to represent a judgment on the degree of influence of a specific factor on that to which it was linked, and (iii) the polarity of the links, assumed to be positive while a minus sign was used to indicate negative polarity. This approach allowed the stakeholder group to formalise their understanding of the conceptual and causal relationships between different components affecting the system (“irrigated agriculture”) in Malta. It also encouraged participants to be explicit in their system description, taking into account the variables and/or feedback that might previously have been ignored but perceived by other stakeholders.

\subsection{Stakeholder questionnaire}

The stakeholder consultation via questionnaire was designed as a follow-up to the Delphi and FCM exercises, but with an emphasis on the Maltese policy framework. The aim of the questionnaire was to incorporate available data and information on the current Maltese policy context and solicit the stakeholders' views and feedback. Key informants including researchers who had previously conducted a stocktaking analysis of national policies were involved in finalizing the questionnaire and identifying target sectors as respondents. The questionnaire included both closed and open questions and ensured response anonymity. Respondents were assured confidentiality with respect to information that would might be published or shared with third parties. The questionnaire was distributed online through Google Forms and in print to farmers to maximise the response rate. The questionnaire aimed to gather feedback regarding national policy achievements, governance and the actions necessary to support appropriate water use and management. Various advantages are reported in the literature (Gillham, 2007; Rowley, 2014) on the use of questionnaire-based approaches, such as the ability to include individuals from a range of socio-economic and demographic backgrounds and with varying levels of experience, the ease of distributing and completing a questionnaire in a variety of formats, flexibility to complete the questionnaire when convenient and the anonymity it provides stakeholders to share their views. In all, 44 individuals participated with their feedback solicited through ten themes: (i) participant profiling, (ii) most important domain in Malta, (iii) degree of awareness of the need for a national management plan/policy for water resources, (iv) most important target group to increase awareness of water resource management/use, (v) stages of formulation and approval for enabling instruments for water resources management, (vi) most appropriate actions for efficient water use/management, (vii) the state of implementation programs and stakeholder participation, (viii) the status of 
implementation of the water governance instruments to enable society to respond to political, economic or environmental uncertainty and change, (ix) degree of agreement with existing policies, and (x) personal views regarding actions needed by the public administration, private sector, civil society and research to better manage access to groundwater abstraction for irrigation without impacting on the environment.

\subsection{Stakeholder backcasting exercise}

The aim of this second workshop was to discuss and analyse the current situation of the agricultural sector to identify measures that could feasibly guarantee adequate water availability in the medium-term (2030). For this, a backcasting approach was used to structure and guide discussions amongst 24 stakeholders with interests in primary production, processing, water regulation and policy formulation. As recommended by Höjer and Mattsson (2000) and Quist et al. (2011), the exercise included two discrete steps: (i) the development of a desirable image of the future, reflecting a consensus of participants and (ii) a backward analysis of how this vision might then be realised. A description of the method used is given in van Vliet and Kok (2015). In considering a medium-term societal problem it was important to explore the desirability and feasibility of alternative futures. This led to an approach that was explicitly normative, which had the added advantage of introducing the question of policy choice into the analysis.

The backcasting technique involved the stakeholders identifying a set of interim objectives, actions and policies that would be necessary to achieve the overall goal. Their opinions were collated and discussed to allow each participant to explain why these preconditions or requirements were necessary from their perspective. The future goal was defined during an open debate amongst participants and defined as "adequate water availability for the future of Maltese agriculture". All participants agreed that a long-term vision to 2050 was unrealistic, so a more tangible medium-term target (2030) was agreed. Each milestone, action and policy was then defined on a 5 year timeline $(2020,2025$ and 2030) and the causal connections between each milestone action and policy were established, working backwards towards the earliest changes that would be needed. During the backcasting exercise, stakeholders were also asked to identify barriers that might constrain realising the milestones. The backcasting approach coerced participants to pass through a process of learning in which their desired future reflected a product of the process of trying to reach it. The desirability of a given set of future conditions was not determined in advance but emerged as a result of negotiation with the consequences of different choices. The outputs from the backcasting exercise were later refined within a 
timeline containing all components (milestones, policies and actions), causal links and obstacles.

\section{Results and Discussion}

\subsection{Delphi analysis and fuzzy cognitive mapping}

The main issues impacting on water use and management in irrigated agriculture and the potential solutions identified by stakeholders through the Delphi analysis, are summarised in Table 1 and Table 2, respectively. A large number of issues were identified, reflecting the diversity of backgrounds, and specific stakeholder interests and perspectives - these were clustered into six main categories, spanning policy, water management, water resources, technology uptake, knowledge translation and socio-technical components (Table 1). Most comments were directed towards agri-environmental or water policy with a lack of political will, awareness or funding support highlighted as major barriers, particularly in the context of supporting new infrastructure investment. Moreover, the need for a national water management plan and the lack of groundwater abstraction management were identified as major issues. Closely linked were (i) perceptions of inadequate ongoing groundwater monitoring (ii) a poor understanding of the impacts of increasing salinity on crop yields and (iii) water quality issues regarding diffuse pollution and nutrient leaching from agriculture. At the farm-scale, a number of important management and technology issues were raised, including the need for better practical guidance on irrigation scheduling, measures to reduce water losses and improve water and nutrient use efficiency, and promoting rainwater harvesting. Malta currently lacks any formal training and extension service which constrains the farming sector's ability to trial and adopt new innovations in water management or to benefit from relevant research. Finally, an ageing sector holding entrenched traditional views was perceived to create an inevitable barrier towards the transition of an agricultural sector that would need to be more progressive, marketfocused and orientated towards "adding value" as well as being able to develop climate smart approaches to cope with future climate uncertainty.

In terms of proposed solutions (Table 2), these centred on fostering stronger multi-sectoral cooperation and awareness of the water challenges facing competing business interests, supporting a more integrated approach to water management with sharing of data and knowledge (preferably though a hub), raising knowledge in the farming community regarding climate impacts and agricultural sector adaptation options/responses, and co-creation of a strategic programme of research to promote innovations in crop and water management. Aligned with building research capacity, the need to empower farmers was clearly highlighted, 
to enable working collaboratively on resolving water resources through, for example, the formation of water user associations, and the fostering of stronger links with the water regulatory agencies. These reiterate Malta's lack of cohesive planning in terms of sectorial participation and involvement in developing a viable strategy for agriculture. The proposed solutions confirm that an improved sharing of knowledge coupled with stakeholder experiences are a vital step in resolving the issues. This is an important realisation for Malta, where due to fragmented decision-making at national, strategic and policy levels, such issues are tackled in isolation and stakeholders remain uninformed and unengaged in the process. Under such circumstances, real needs - technical or otherwise- cannot be properly identified and thus, issues that are pertinent to improved management of water resources remain unresolved.

The outcomes from the FCM are summarised in Figure 1, showing the direction and strength of causal links between water-related problems and solutions. Performing an analysis of the map allowed to define the central issue identified by stakeholders. The analysis looked at concepts that are linked to each preceding concept, irrespective of direction. Links where causality may act in either direction were treated as merely a link and not bi-directional. The highest number of causal links in the map was associated to the "policy" issue (nine links), indicating that participants considered "policy" to be the main issue requiring attention, and from which a genuine process of implementation of sustainable management of water for the agricultural sector could then commence. The links between policy and potential solutions including research and innovation, alternative water sources, climate adaptation and capacity building indicate that both policy will and interest are needed for funding and driving forward important initiatives including research into alternate water sources, developing innovative water application systems supported by farmer training, and climate adaptation measures relating to crop productivity, drought tolerance and coping with extreme events.

An important link identified from the FCM was the high influence that policy can exert towards supporting investments in public infrastructure. Malta could benefit from such investments, for example, in infrastructure for water harvesting and storage, as there are currently no reservoirs on the island and significant resources are used to discharge stormwater to sea. During discussions the stakeholders argued for the need for new infrastructure to support water delivery to farmers, for example, via sources of supply from treated wastewater. However, such a development would need significant planning and investment, as it would require a separate piped distribution network to farm holdings and on-farm storage. Taking into account the small scale of farm units and large number of enterprises on the island, a solution 
implemented via a water user association type arrangement may improve the feasibility and cost-efficiency of such an approach.

A high influence causal link was also identified between the problems of policy and water regulation. The problem of water regulation mostly refers to the lack of groundwater abstraction control, which constitutes a major water resources management issue for Malta. Groundwater remains unregulated and free, with costs only incurred for pumping. There was reported to be a lack of legislation for control and monitoring and thus no incentives for farmers to reduce consumption and avoid over-exploitation. The main solution proposed to reduce water over-exploitation was a program of "education and awareness", involving the agricultural community and water users to raise awareness of the water challenges facing Malta and involving the policy makers to support implementation measures and monitoring.

Climate change was also identified as one of the main driving forces affecting the system, through its causal links to issues of water availability, the state of the environment and policy (Figure 1). In terms of water and the environment, negative impacts of climate change were expected for both water quantity and quality, particularly during summer when pressures on groundwater, water scarcity and salinity levels were all high, with consequent impacts on productivity. However, the stakeholders considered that the risks associated with climate change also had the potential to exert a strong influence on the political will to develop and implement a holistic water management plan, based on active engagement with the agricultural community, as shown by the direct and high influence link between climate change and policy. Another important issue highlighted by participants was a lack of information on the quality and quantity of groundwater (expressed through information and knowledge accessibility), which needs to be assessed, through for example, simulation models, farmer surveys and better in-situ monitoring. The second Malta Water Catchment Management Plan (ERA, 2011) confirmed that there was a data gap since the actual abstracted volumes from the aquifers were not known due to a limited and incomplete dataset.

According to the group discussions, policy had a direct influence on "research and innovation", and should be oriented to address existing gaps in knowledge that farmers currently face in terms of implementing more efficient irrigation application methods, and more targeted regulation to improve water efficiency. As reported by Attard et al. (2007), irrigation practices and methods have been identified as fundamental factors influencing water efficiency. Evidence from farmer representatives confirmed low levels of knowledge on irrigation management including how to objectively assess crop water requirements and the benefits of 
irrigation scheduling. The need for "information and knowledge accessibility" drawing also on international experience was strongly endorsed.

The direct link between "farmer cooperation and empowerment" and "information and knowledge accessibility" reflects the major difficulties in accessing data relevant to water regulation. Data were either unavailable, of poor quality and/or dispersed between different institutions. Accurate data would provide a foundation for authorities to implement monitoring and control (i.e. location of farms in close proximity of water sources for nitrate contamination control, and location and number of boreholes with abstraction volumes). Part of the data accessibility problem was reported on the lack of communication and cooperation between different institutions. Indeed, a lack of coordination was identified not only vertically between farmers and institutions but also horizontally between different governmental institutions (ministries and water authorities).

\subsection{Stakeholder questionnaire}

Valuable insights and feedback were gathered from stakeholders on their opinions regarding national policy achievements, governance and the actions needed to support appropriate water use and management in Maltese agriculture. The questionnaire data highlighted repeated stakeholder requests for a national water management plan. In addition, various programs that have used stakeholder participation to inform water governance instruments have also not yet been implemented. From the stakeholders' perspective, the fundamental challenges were to reduce pressure on the aquifers whilst maintaining reliable and adequate water supplies to end users, and to establish a water management planning process that would take into account the economic and environmental conditions necessary to enable society to respond to future uncertainty. Stakeholders indicated that an effective water policy would need to address the following key elements: improved governance and awareness, investments for new infrastructure, capacity building for farmers, promotion of alternative water sources, targeted interventions, cooperation and empowerment among farmers, and knowledge exchange and sharing of experiences from other countries. An awareness raising campaign to support efficient water management was highlighted by half the stakeholders; the target group identified for action to increase awareness were policy makers.

Based on stakeholder opinion, water governance will only improve if there is wider acceptance of the need for a water policy that includes regulations. For this to happen, regulations must be seen to be equitable and just. Furthermore, there must be political will to enforce such regulations, according to sustainable abstraction levels. It is apparent that improved levels of 
collective responsibility will be required for managing and protecting Malta's water resources. Finally, stakeholders argued that effective management of water resources would only be possible once data on the status and trends in water resources and information on current and future demand projections were readily available. The importance of decision-makers at all levels in having a robust understanding of the characteristics of the water resource systems they manage and the consequences for different courses of action were also highlighted. Although some water-related information is available, stakeholders regarded the evidence as being too fragmented and difficult to access.

\subsection{Backcasting exercise}

The backcasting output is presented in Figure 2. To achieve adequate water availability for agriculture by 2030, improved water use and control, especially regarding groundwater abstractions was identified as the fundamental milestone. This needs to be supported by actions to effectively monitor and control groundwater abstractions, supported by a dedicated national policy to regulate and control groundwater (Figure 2). Boreholes with high abstraction rates should be identified, licensed and metered. Participants also agreed on the need for tariffs together with other demand-management instruments to reduce groundwater use to sustainable levels. An important milestone for 2030 was the increased use of rainwater harvesting, which could lead to more effective use of water for irrigation (Galdies et al., 2016). The construction of new rainwater harvesting infrastructure would need to be supported by a national funding. The latter would also be necessary to fund a new water distribution network for agriculture. This network would supply alternate sources of water and improve water efficiency through reductions in leakage, and reducing illegal abstractions, resulting in a more economic delivery service.

By 2025, participants identified three milestones, namely (i) the improvement in communication and dialogue between stakeholders (ii) the development and adoption of different strategies for irrigation and cultivation, and (iii) a centralised approach to water management on the island. In this context, participants argued that policies and processes that have the most potential to affect the supply of or demand for water resources need much greater alignment. Participants argued that the involvement of stakeholders in water resource planning could facilitate better communication through the establishment of a platform, including representatives from all levels. This would lead to better involvement by stakeholders in the decision-making process and stronger ownership of plans and regulations. For irrigation, participants referred to the need for adoption of practices that would improve 
water efficiency and support a reduction in demand by farmers and the agricultural sector as a whole. Aligned to this, participants considered the importance of crop varieties and suitable crop rotations and soil management practices being better adapted to local conditions, and the challenge of reconciling water scarcity with the cultivation of high water demanding crops. Strategies to support irrigation and cultivation would have to be supported by policies financing research and appropriate management of water and land use.

The timescales for action were also identified as a critical strategic issue. For example, improving the availability of data to support improved decision making and supporting the empowerment of farmers were seen as two key activities that needed rapid short-term implementation if all the milestones for 2025 were to be met. Participants also highlighted the need to improve access to water-related information for including quality assurance on data. This was perceived as being fundamental to achieving more efficient and effective national water governance. For example, providing stakeholders with access to data on the state of groundwater resources and irrigation demands would increase the levels of collective responsibility for managing shared water resources. Participants also expressed their concern regarding the current approach whereby the agricultural sector operates in isolation, with the many individual businesses denying themselves the opportunity to share information and promote collaborative practices for common benefit. Participants were convinced that only a targeted national policy would be able to support the consolidation of farmer cooperatives and creation of water user associations. Finally, stakeholders were asked to identify any obstacles that could hamper the realization of milestones. These included a lack of institutional trust, lack of cooperation and communication, high costs for rainwater harvesting infrastructure, lack of inter-sectoral policies, further fragmentation of agricultural land use, lack of professional skills, and limited access to land for new entrants into the sector (especially for young/new farmers).

\section{Conclusions}

This research represents the first attempt to conduct a participatory stakeholder-led engagement study to investigate agricultural water policy and practice issues in Malta. Our analysis provides a robust understanding of the water-related issues currently impacting on irrigated agriculture on the island and the actions needed from a regulatory, technical and industry perspective to improve the future sustainability from the stakeholders' perspective. This research provides novel insights on the causal relationships between water-related problems and potential solutions for Malta, and the actions required to achieve adequate water availability by 2030 - a time horizon that aligns well with the policy making agenda. The 
findings will provide valuable insights to inform future practices and policies regarding agricultural water management in Malta, and have direct relevance for other Mediterranean countries facing similar agricultural water challenges. Apart from policy, water scarcity and deterioration of water quality are perceived as two priority issues that continue to threaten the sustainable development of irrigated agriculture. However, in this context, social aspects have emerged as a key constraint. In Malta, the combination of a large number of individual holdings, small farm sizes and an aging sector demographic have created major barriers to the willingness of farmers to adopt new technologies, improve management practices and their receptiveness to new innovations. Significant effort will be needed to engage with the next farming generation to ensure that future Maltese water policies have the necessary level of support at farm level. 


\section{References}

Alcon, F., Tapsuwan, S., Martínez-Paz, J.M., Brouwer, R., de Miguel, M.D., 2014. Forecasting deficit irrigation adoption using a mixed stakeholder assessment methodology. Technol.

Forecast. Soc. Change 83, 183-193. https://doi.org/10.1016/j.techfore.2013.07.003

Attard, G., Mangion, J., Micallef, P., 2007. Water Use Efficiency and Water Productivity in Malta. Options Mediterr. Ser. B 57, 153-162.

Carley, K., Palmquist, M., 1992. Extracting, presenting and analyzing mental models. Soc.

Forces 70, 601-636. https://doi.org/https://doi.org/10.1093/sf/70.3.601

Carvalho, J.P., Tomè, J.A., 1999. Rule based fuzzy cognitive maps-fuzzy causal relations. M. Mohammadian (Ed.), Comput. Intell. Model. Control Autom.

Conrad, E., Cassar, L.F., 2014. Decoupling economic growth and environmental degradation: Reviewing progress to date in the small Island state of Malta. Sustain. 6, 6729-6750.

https://doi.org/10.3390/su6106729

Dwyer, J., Temple, M., Jones, J., Muscat, R., Cordina, G., Vella, S., 2014. Towards a New Agricultural Policy for Malta: Final report.

EC, 2000. DIRECTIVE 2000/60/EC OF THE EUROPEAN PARLIAMENT AND OF THE COUNCIL.

ERA, 2011. The 2 nd Water Catchment Management Plan for the Malta Water Catchment District $2015-2021$.

FAO, 2006. Malta Water Resources Review.

Galdies, C., Said, A., Camilleri, L., Caruana, M., 2016. Climate change trends in Malta and related beliefs, concerns and attitudes toward adaptation among Gozitan farmers. Eur. J. Agron. 74, 18-28. https://doi.org/10.1016/j.eja.2015.11.011

Gatt, K., 2016. Social network analysis as a tool for improved water governance in Malta. Int. J. Soc. Syst. Sci. 8, 131. https://doi.org/10.1504/ijsss.2016.077013

Gillham, B., 2007. Developing a questionnaire, 2nd ed. Continuum Intenational Publishing Group, London.

Hallett, S.H., Sakrabani, R., Thompson, A.J., Deeks, L.K., Knox, J., 2017. Improving Soil and Water Management for Agriculture : Insights and Innovation from Malta. MCAST J. Appl. Res. Pract. 40-59. 
Höjer, M., Mattsson, L.G., 2000. Determinism and backcasting in future studies. Futures 32, 613-634. https://doi.org/10.1016/S0016-3287(00)00012-4

Khadra, R., D’Agostino, D.R., Scardigno, A., Lamaddalena, N., 2011. Down-scaling panEuropean water scenarios to local visions in the mediterranean: The Candelaro basin case study in Italy. J. Water Clim. Chang. 2, 180-188. https://doi.org/10.2166/wcc.2011.008

Kosko, B., 1993. Fuzzy thinking: The new science of fuzzy logic, Hyperion Press (New York). https://doi.org/10.1016/s0967-0661(96)90022-2

MBB, 2014. Recommendations - National Water Management Plan By the Malta Business Bureau's EU LIFE + Investing in Water Project March 2014.

MEPA, 2011. The Water Catchment Management Plan for the Maltese Islands.

MESDC, 2018. National Agricultural Policy for the Maltese Islands 2018 -2028. Malta.

Nowack, M., Endrikat, J., Guenther, E., 2011. Review of Delphi-based scenario studies:

Quality and design considerations. Technol. Forecast. Soc. Change 78, 1603-1615. https://doi.org/10.1016/j.techfore.2011.03.006

Papadimitriou, L., D’Agostino, D., Borg, M., Hallett, S., Sakrabani, R., Thompson, A., Knox, J., 2019. Developing a water strategy for sustainable irrigated agriculture in Mediterranean island communities - Insights from Malta. Outlook Agric. 1-9. https://doi.org/10.1177/0030727019841060

Quist, J., Thissen, W., Vergragt, P.J., 2011. The impact and spin-off of participatory backcasting: From vision to niche. Technol. Forecast. Soc. Change 78, 883-897. https://doi.org/10.1016/j.techfore.2011.01.011

Roberts, F., 2015. The questionnaire method, in: Structure of Decision. Princeton University Press, United States, pp. 333-342.

Roberts, L., Cremona, M., Knox, G.J., Scicluna, M., Bonello, M., Bugeja, S., Calleya, S., Camilleri, J., Dingli, P.C., White, J.C., Debono, G., Falzon, M.A., Frendo, M., Galea, M., Sammut, J., Tabone, J. V, Tabone, P., Vassallo, C., Vassallo, J., Zahra, J.F.X., 2015. Why Malta'S National Water Plan Requires an Analytical Policy Framework.

Rowley, J., 2014. Designing and using research questionnaires. Manag. Res. Rev. 37, 308-330. https://doi.org/10.1108/MRR-02-2013-0027

Saliba, R., Callieris, R., D’Agostino, D., Roma, R., Scardigno, A., 2018. Stakeholders' attitude 
towards the reuse of treated wastewater for irrigation in Mediterranean agriculture. Agric. Water Manag. 204, 60-68. https://doi.org/10.1016/j.agwat.2018.03.036

Schneider, M., Shnaider, E., Kandel, A., Chew, G., 1998. Automatic construction of FCMs. Fuzzy Sets Syst. 93, 161-172. https://doi.org/10.1016/S0165-0114(96)00218-7

Swanson, B.E., 2008. Global Review of Good Agricultural Extension and Advisory Practices, FAO (Rome). https://doi.org/10.1080/1389224X.2010.489775

van Vliet, M., Flörke, M., Varela-Ortega, C., Çakmak, E.H., Khadra, R., Esteve, P., D’Agostino, D., Dudu, H., Bärlund, I., Kok, K., 2017. FCMs as a Common Base for Linking Participatory Products and Models, in: Gray, Steven, Paolisso, M., Jordan, R., Gray, Stefan (Eds.), Environmental Modeling with Stakeholders: Theory, Methods, and Applications. Springer International Publishing, Cham, pp. 145-169. https://doi.org/10.1007/978-3-31925053-3_8

van Vliet, M., Kok, K., 2015. Combining backcasting and exploratory scenarios to develop robust water strategies in face of uncertain futures, Mitigation and Adaptation Strategies for Global Change. https://doi.org/10.1007/s11027-013-9479-6 van Vliet, M., Kok, K., Veldkamp, T., 2010. Linking stakeholders and modellers in scenario studies: The use of Fuzzy Cognitive Maps as a communication and learning tool. Futures 42, 1-14. https://doi.org/10.1016/j.futures.2009.08.005

Xerri, F., Jeffrey, P., Smith, H.M., 2016. Unpacking organizational capacity in the context of the Water Framework Directive. Int. J. River Basin Manag. 14, 317-327. https://doi.org/10.1080/15715124.2016.1193508

Zammit, A., 2006. Agriculture without a water policy. Times of Malta. 
Table 1 Stakeholder identified water issues and clusters as part of the Delphi analysis.

\begin{tabular}{|c|c|}
\hline Cluster & Identified issue \\
\hline $\begin{array}{l}\text { Policy (agri- } \\
\text { environmental } \\
\text { and water) }\end{array}$ & $\begin{array}{l}\text { Lack of political will to sustain the agricultural sector, and enforce controls on } \\
\text { illegal groundwater abstraction } \\
\text { Lack of an official water management plan } \\
\text { Lack of adequate legislation regarding use of reverse osmosis } \\
\text { Lack of political awareness relating to water problems faced by farmers } \\
\text { Lack of research funding (some innovative affordable solutions available from } \\
\text { neighbouring countries could be easily adapted to local conditions) } \\
\text { Lack of national water policy (no roadmap) and strategic direction } \\
\text { Lack of funding to support new water infrastructure } \\
\text { Lack of cooperation between policy and farmers } \\
\text { Over relying on reverse osmosis technology, current policy is shifted from } \\
\text { protecting current and new water resources such as sewage treatment }\end{array}$ \\
\hline $\begin{array}{l}\text { Water regulation } \\
\text { (pricing and } \\
\text { abstraction } \\
\text { management) }\end{array}$ & $\begin{array}{l}\text { Unregulated groundwater abstraction } \\
\text { Low pumping costs incentivise over-abstraction } \\
\text { Lack of water pricing to reflect value and scarcity } \\
\text { Lack of accurate, reliable geospatial database to support authorities in } \\
\text { monitoring and controlling water use } \\
\text { Inadequate infrastructure with untreated effluent discharged into the sea } \\
\text { Farmers blamed for high N concentrations in groundwater. Authorities should } \\
\text { consider drainage (domestic leakage) and other pollution sources }\end{array}$ \\
\hline Water availability & $\begin{array}{l}\text { The availability of water is inadequate referred to cash crops } \\
\text { Water is not sufficient especially in summer } \\
\text { Saline water from aquifer is the main water source (no alternatives) } \\
\text { Unreliable water supplies for processing plants }\end{array}$ \\
\hline $\begin{array}{l}\text { On-farm water } \\
\text { management and } \\
\text { technology }\end{array}$ & $\begin{array}{l}\text { Inadequate water distribution system for supplying farms } \\
\text { High water losses from existing irrigation systems } \\
\text { Small farm size holdings limit opportunity for rainwater harvesting Inappropriate } \\
\text { water consumption (misuse and abuse) in agriculture and other sectors } \\
\text { Farmers do not know how much water they are applying nor how much water is } \\
\text { needed for each crop } \\
\text { Lack of information, measurement tools and monitoring systems } \\
\text { Currently slurry application is banned in Malta and is discharged into the } \\
\text { sewerage system. Anaerobic digestion plants may be a solution }\end{array}$ \\
\hline $\begin{array}{l}\text { Information and } \\
\text { knowledge } \\
\text { accessibility }\end{array}$ & $\begin{array}{l}\text { Lack of knowledge efficient water management practices } \\
\text { Lack of understanding on how water is used in the agricultural sector } \\
\text { Lack of advisory services to support farmers in reducing water use } \\
\text { Lack of technical knowledge at farm level (crop water requirements) } \\
\text { Traditional mind-sets difficult to promote and implement change }\end{array}$ \\
\hline $\begin{array}{l}\text { State of } \\
\text { environment }\end{array}$ & $\begin{array}{l}\text { High salinity levels in irrigation water impacting on crop yield and quality and } \\
\text { soil structure } \\
\text { Groundwater pollution from agriculture (nitrates, pesticides and herbicides) } \\
\text { Lack of certified laboratories for water quality testing }\end{array}$ \\
\hline $\begin{array}{l}\text { Over-exploitation } \\
\text { of water }\end{array}$ & $\begin{array}{l}\text { Over extraction of water from the aquifer including non-agricultural uses, } \\
\text { leading to bad quality of water (unsustainable recharge) } \\
\text { Abstraction of water for agriculture is not managed in a sustainable manner } \\
\text { Use of un-regulated boreholes by various sectors, but only agriculture blamed }\end{array}$ \\
\hline Climate change & $\begin{array}{l}\text { Increase of water requirements } \\
\text { Uncertainty in crops yield } \\
\text { Unpredictability of water resources availability }\end{array}$ \\
\hline
\end{tabular}


Table 2 Stakeholder identified potential solutions to improve water management for agriculture within the Delphi analysis.

\begin{tabular}{|c|c|}
\hline Cluster & Identified solution \\
\hline $\begin{array}{l}\text { Education and } \\
\text { awareness }\end{array}$ & $\begin{array}{l}\text { Establish cross-ministerial water committee with clear roles and } \\
\text { responsibilities regarding national and EU legislation, infrastructural } \\
\text { investments, monitoring, and data management } \\
\text { Establish authorities responsible for data compilation, processing and } \\
\text { dissemination and EU funding programmes } \\
\text { Encourage closer dialogue, cooperation and communication between } \\
\text { farmers and regulatory authorities } \\
\text { Investment to support implementation measures and policy monitoring } \\
\text { Engage consumers to raise awareness of water challenges in Malta }\end{array}$ \\
\hline $\begin{array}{l}\text { Integrated approach at } \\
\text { policy level }\end{array}$ & $\begin{array}{l}\text { Enhanced cross-sectoral collaboration to identify solutions and strategies } \\
\text { that take into account environmental factors } \\
\text { Better coordination of resources and knowledge sharing } \\
\text { Support more integrated holistic approaches to realise a strategic plan for } \\
\text { water in Malta }\end{array}$ \\
\hline Climate adaptation & $\begin{array}{l}\text { Selecting crops that are adapted to a changing climate } \\
\text { Developing strategies to cope with increased water scarcity and unreliability } \\
\text { in supply }\end{array}$ \\
\hline $\begin{array}{l}\text { Research and } \\
\text { innovation }\end{array}$ & $\begin{array}{l}\text { Support field research to assess salinity impacts on crop production } \\
\text { Promote research to develop innovations in crop production, precision } \\
\text { irrigation and on-farm water storage and recycling } \\
\text { Promote rainwater harvesting and storage } \\
\text { Investigate opportunities for renewable desalination } \\
\text { Support construction of AD plants with EU support } \\
\text { Introduce more drought and salt tolerant seed varieties } \\
\text { Provide better incentives for farmers to modify farming practices } \\
\text { Establish technical support to farmers (extension services) } \\
\text { Sensor technology for soil moisture monitoring } \\
\text { Move towards lower water footprint production } \\
\text { Support creation of knowledge hub for agricultural information } \\
\text { Implement research programmes to address knowledge gaps and establish } \\
\text { demonstration sites for farmer training/outreach } \\
\text { Improve laboratory and research facilities to support farmers } \\
\text { Support applied research and knowledge translation } \\
\text { Greater use of social media to disseminate information to farmers }\end{array}$ \\
\hline $\begin{array}{l}\text { Farmer cooperation, } \\
\text { and empowerment }\end{array}$ & $\begin{array}{l}\text { Farmer representatives to establish public/private partnerships to drive } \\
\text { change } \\
\text { Support agricultural sector to increase water use efficiency, improve crop } \\
\text { quality, better control and awareness by consumers } \\
\text { Establish farmer water user associations to foster collaboration and closer } \\
\text { consultation with regulators on water allocation and management }\end{array}$ \\
\hline $\begin{array}{l}\text { Alternative water } \\
\text { sources }\end{array}$ & $\begin{array}{l}\text { Storing rainwater } \\
\text { Renewable desalination }\end{array}$ \\
\hline
\end{tabular}


Figure 1 Fuzzy cognitive mapping to reflect the causal relationships between water-related problems (blue boxes) and potential solutions (green boxes) in Malta. The three levels of thickness of the arrows represent the strength of the causal links: high, medium or low influence of a specific factor on the one it links to. Negative polarity is indicated by a minus sign, otherwise the polarity of the link is positive.

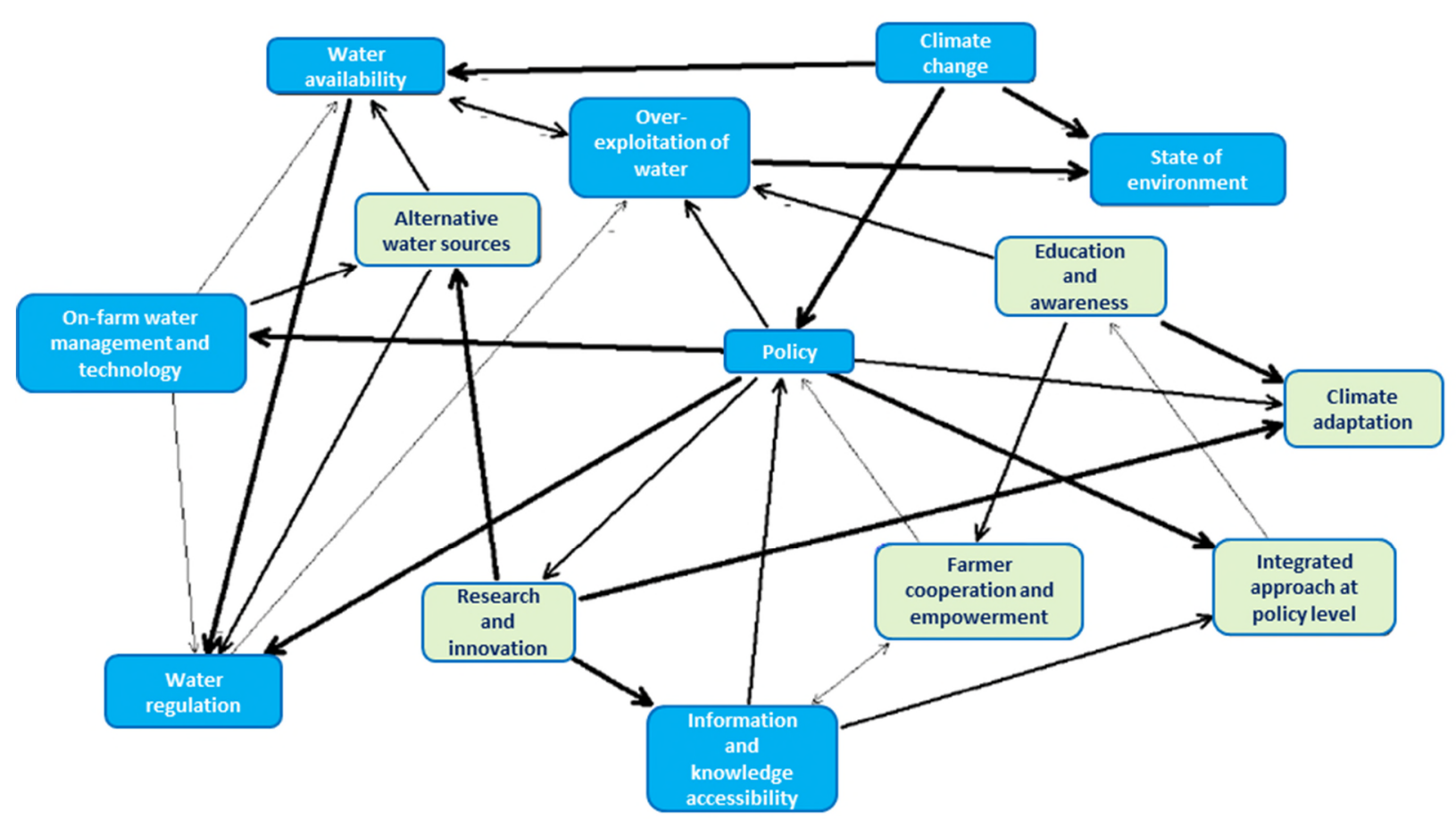


Figure 2 Backcasting timeline to guarantee adequate water availability for agriculture in the medium-term (2030), developed by agricultural policy and practitioner stakeholders showing actions (blue), milestones (orange), and policies (green).

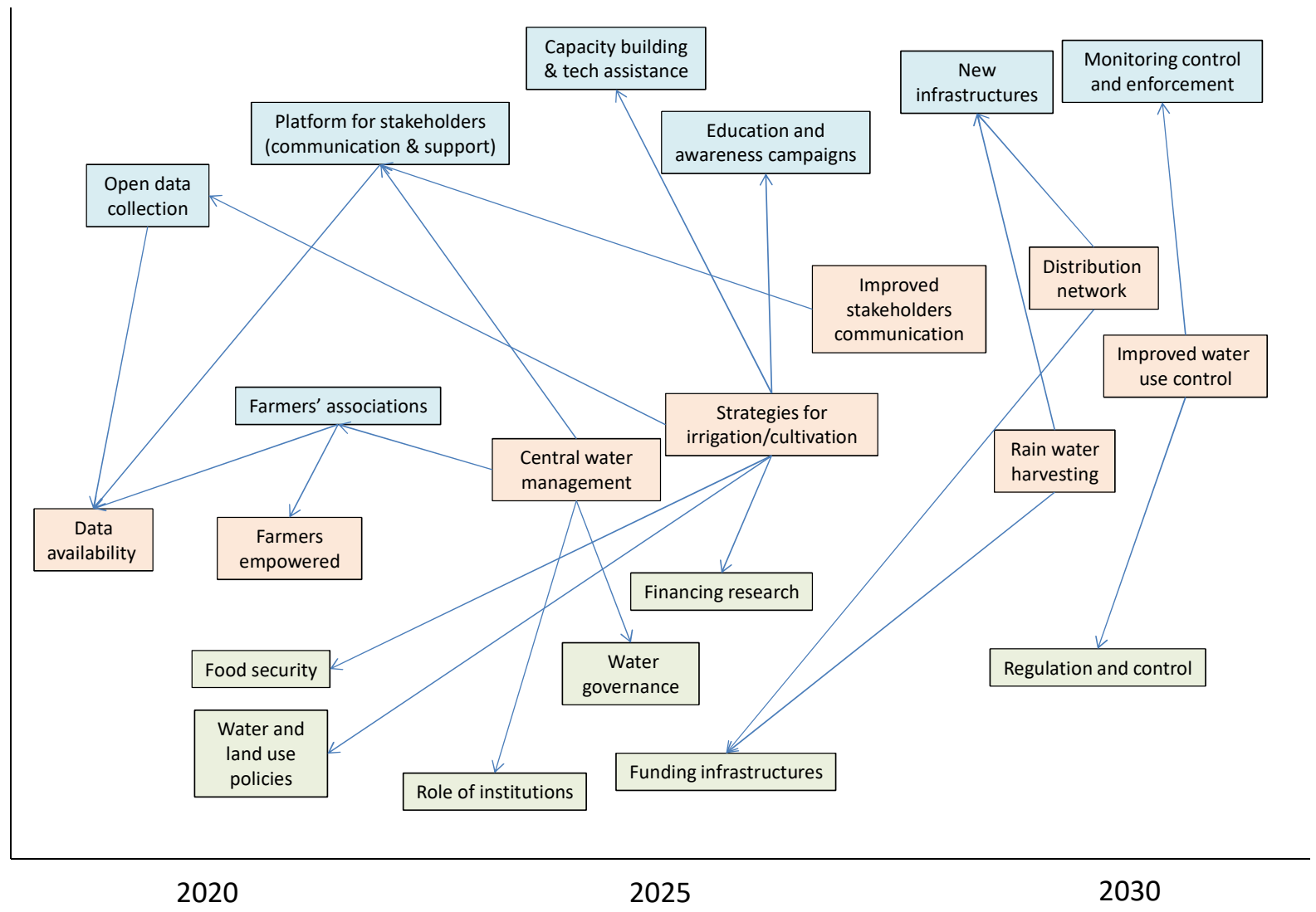

